\title{
Expenditure Cascades
}

\author{
Robert H. Frank ${ }^{1}$, Adam Seth Levine ${ }^{2}$ and Oege Dijk ${ }^{3}$ \\ ${ }^{1}$ H. J. Louis Professor of Management and Professor of Economics, Johnson \\ Graduate School of Management, Cornell University, 327 Sage Hall, Ithaca, \\ NY14850,USA; rhf3@cornell.edu \\ ${ }^{2}$ Assistant Professor, Department of Government, Cornell University, \\ 302 White Hall, Ithaca, NY 14850,USA; ASL22@cornell.edu \\ ${ }^{3}$ Radboud University Nijmegen, Institute for Management Research, Thomas van \\ Aquinostraat 5, 6500HK Nijmegen, The Netherlands; o.dijk@fm.ru.nl
}

\begin{abstract}
Prevailing economic models of consumer behavior completely ignore the welldocumented link between context and evaluation. We propose and test a theory that explicitly incorporates this link. Changes in one group's spending shift the frame of reference that defines consumption standards for others just below them on the income scale, giving rise to expenditure cascades. Our model, a descendant of James Duesenberry's relative income hypothesis, predicts the observed ways in which individual savings rates respond to changes in both own and others' permanent income, as well as numerous other stylized fact patterns that are difficult to reconcile with prevailing models.
\end{abstract}

Evaluative judgments are known to depend heavily on context. For example, the same car that would have been experienced by most drivers as having brisk acceleration in 1950 would seem sluggish to most drivers today. Similarly, a house of given size is more likely to be viewed as adequate the larger it is relative to other houses in the same local environment. And an effective interview suit is simply one that compares favorably with those worn by other applicants for the same job.

ISSN 2326-6198; DOI 10.1561/105.00000003

(C) 2014 R. H. Frank, A. S. Levine and O. Dijk 
Although the link between context and evaluation is uncontroversial among behavioral scientists, traditional economic models completely ignore it. These models assume that each person's consumption spending is completely independent of the spending of others.

In contrast, James Duesenberry's relative income hypothesis explicitly acknowledges the link between context and evaluation (Duesenberry, 1949). In this paper we employ a variant of his model to derive and test the proposition that context shapes spending patterns. In this effort, we exploit data that allow us to quantify the substantial increases in local income inequality that have occurred in recent decades. According to the life-cycle and permanent income hypotheses, these increases should have no effect on individual spending decisions. In contrast, the relative income hypothesis predicts a substantial change in spending patterns in response to these changes. From statistical analysis based on U.S. Census data for the 50 states and 100 most populous counties, we find evidence that rapid growth of income among top earners in recent decades has stimulated a cascade of additional expenditure by those with lower earnings.

\section{Expenditure Cascades}

Friedman's (1957) permanent income hypothesis continues to provide the foundation that underlies modern economic analysis of spending and savings. According to this model, a family spends a constant proportion of its permanent income, rich or poor. The model thus predicts that savings rates should be independent of household income and should remain stable over time.

Both predictions are at odds with experience. It has long been shown, for example, that savings rates rise sharply with permanent income in cross-section data. ${ }^{1}$ Savings rates have also shown substantial variation over time. According to U.S. Department of Commerce estimates shown in Figure 1, the aggregate personal savings rate has fallen from an average of roughly 10 percent in the early 1970s to roughly 5 percent today.

The recent experience of middle-income families also casts doubt on Friedman's portrayal of the relationship between household income and spending. In 1980, the

1 For example, see Mayer (1972). Mayer rejects Friedman's original conjecture that this pattern is explained by the unresponsiveness of spending to transitory income changes, arguing that it cannot explain why people in high-income occupations save at higher rates than people in low-income occupations. 


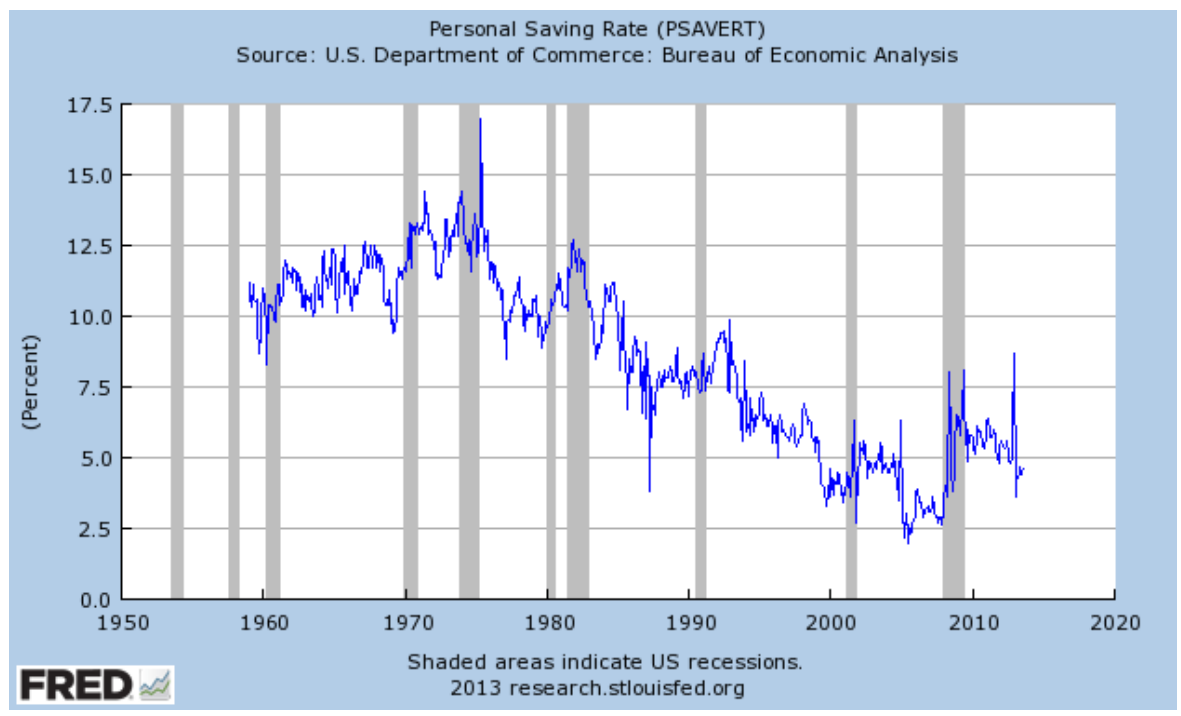

Figure 1. The personal savings rate in the United States.

median size of a newly constructed house in the United States was approximately 1600 square feet. By 2001, however, the corresponding figure had grown to over 2100 square feet - more than twice the corresponding growth in median family earnings (Center on Budget and Policy Priorities, 2003). During the same period, the median household experienced substantial growth in consumer debt. One in five American households currently has zero or negative net worth.

Why is consumption expenditure so much higher than predicted by traditional economic models? We use the term expenditure cascade to describe a process whereby increased expenditure by some people leads others just below them on the income scale to spend more as well, in turn leading others just below the second group to spend more, and so on. Our expenditure cascade hypothesis is that a pervasive pattern of growing income inequality in the United States has led to the observed decline in savings rates.

\section{An Illustrative Model}

Consider an economy with $N$ consumers arranged in descending order with respect to their permanent incomes. According to the permanent income hypothesis, 
individual $i$ 's current consumption, $C_{i}$, is proportional to his/her permanent income, $Y_{i}$ :

$$
C_{i}=k Y_{i}
$$

where $k$ is a parameter unrelated to permanent income level or rank. According to this model, each consumer's spending is independent of all income levels other than his/her own:

$$
d C_{i} / d Y_{j}=0, \quad \forall i \neq j .
$$

Thus, according to the permanent income hypothesis, changes in the distribution of income should have no effect on individual spending levels. If someone's income does not change, his/her spending will remain the same, even if the income and spending levels of others change substantially.

In contrast to this baseline model, we consider the following variant of the relative income hypothesis:

$$
C_{i}=k(1-a) Y_{i}+a C_{i+1},
$$

where $C_{i}$ and $Y_{i}$ again denote current consumption and permanent income levels of the $i$ th consumer, and where $C_{i+1}$ denotes the current consumption level of the individual whose permanent income ranks just ahead of $i$ 's own. The parameter $k$ is defined as before, and the parameter $a$ (where $0 \leq a \leq 1$ ) represents the extent to which each individual's spending is influenced by the spending of those with higher incomes. For $a=0$, the spending of others has no influence at all, and the model collapses to the permanent income hypothesis. For $a=1$, an individual's spending level is determined entirely by the spending level of the individual whose income just outranks his own.

In a crude way, this model captures what are perhaps the two most robust findings from the behavioral literature on demonstration effects: (1) the comparisons that matter most are highly localized in time and space; and (2) people generally look to others above them on the income scale rather than to those below (Frank, 1985, Chapter 2).

A more realistic model would allow explicitly for the possibility that a consumer is also influenced by others more distant from the individual who ranks just ahead of him. But even in our simple model, the influence of such others is captured indirectly through the implied chain of step-by-step comparisons explicit in the model. For example, if a given consumer were to spend an additional $\$ 100$, the spending levels of the four individuals ranked just below him/her would go up by $100 a, 100 a^{2}, 100 a^{3}$, and $100 a^{4}$ dollars, respectively.

For illustrative purposes, we consider a hypothetical 11-member reference group with $k=0.8$ and $a=0.5$. If the highest ranked member in this group consumes 

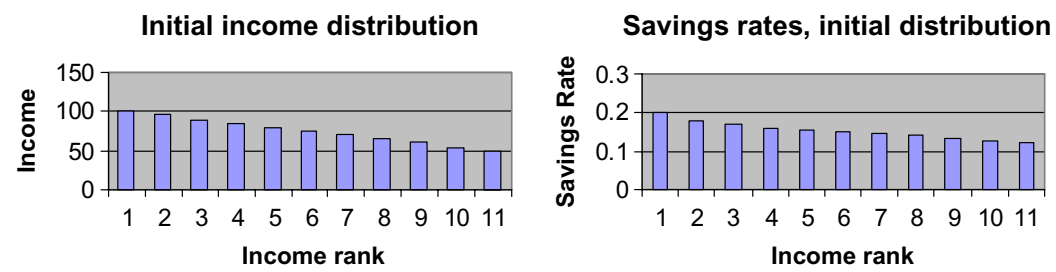

Figure 2. Income rank and savings rates, initial income distribution.

80 percent of his income, lesser-ranked members will consume according to Equation (3), which, for the assumed parameter values, simplifies to

$$
C_{i}=0.4 Y_{i}+0.5 C_{i+1}, \quad i=1, \ldots, N-1 .
$$

For the initial income distribution shown in the left panel of Figure 2, the corresponding savings rates are shown in the right panel. They range from a high of 20 percent for the highest ranked member (the savings rate that we would see for everyone if the parameter $a$ were equal to zero, as under the permanent income hypothesis), to a low of 12 percent for the lowest-ranked member. The average savings rate for the group is 15.6 percent, or 4.4 percentage points lower than it would have been in the absence of income inequality.

We now alter the initial distribution by increasing the incomes of only the two highest-ranked members. In the new distribution, the highest-ranked member earns not 100, but 150; and the second-ranked member earns not 95 but 120 . The incomes of the other members are the same as in the original distribution. As shown in the right panel of Figure 3, the resulting expenditure cascade lowers the savings rates of all the remaining members. The median earner, with an income of 75 in both the cases, saves at a rate of almost 15 percent under the original distribution, but only 12.3 percent under the new distribution. The savings rate for the group as a
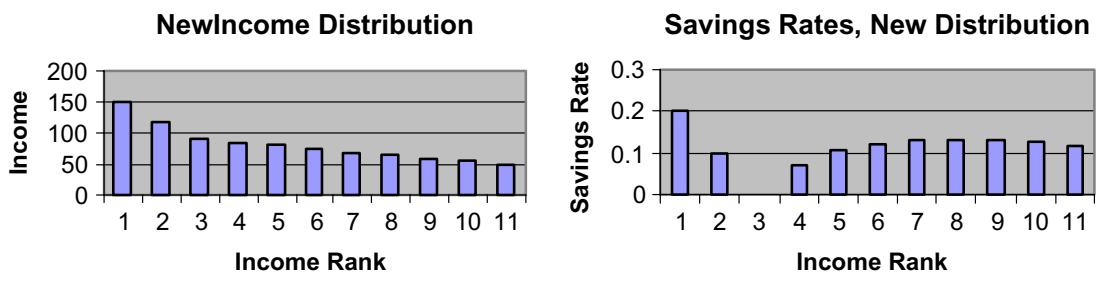

Figure 3. Income rank and savings rates, new income distribution. 
whole is now only 11.6 percent, a full 4 percentage points lower than it was under the original distribution.

As our simple model illustrates, an increase in income inequality could give rise to a reduction in savings rates. In the next section, we examine how the increase in inequality assumed in our illustration compares with the actual recent growth in inequality.

\section{Changing Patterns of Income Growth}

In the United States, income growth from 1945 until the end of 1970s was well described by the famous picket fence chart shown in Figure 4. Incomes grew at about the same rate for all income classes during that period, a little under three percent per year.

That pattern began to change at some point during the 1970s. During the 24-year period shown in Figure 5, the real purchasing power of people at the bottom income distribution remained essentially unchanged, and gains throughout the middle of the income distribution were extremely small. For example, median family earnings were only 12.6 percent higher at the end of that period than at the beginning. Income gains for families in the top quintile were substantially larger, and were larger still for those in the top five percent. Yet even for these groups, income growth was not as great as during the earlier period. The later period was thus a period of both slower growth and much more uneven growth.

Income inequality has also increased in two important ways not portrayed in Figures 4 and 5. One is that changes in the income-tax structure during the Ronald

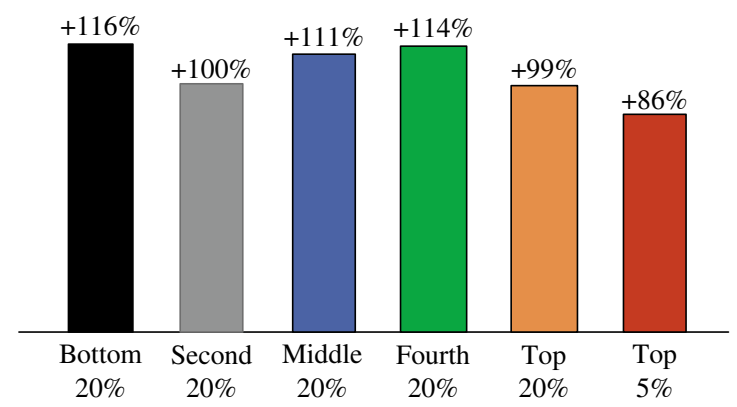

Figure 4. Changes in before-tax household incomes, 1949-1979. Source: http://www.census.gov/hhes/income/histinc/f03.html. 


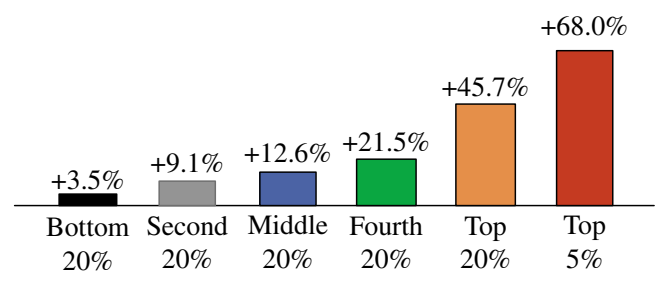

Figure 5. Changes in before-tax incomes, 1979-2003.

Source: http://www.census.gov/hhes/income/histinc/h03ar.html.

Reagan presidency significantly shifted real after-tax purchasing power in favor of those atop the socioeconomic ladder, a change that was reinforced by additional tax cuts targeted toward high-income families during the first term of George W. Bush. A second change not reflected in Figures 2 and 3 is the magnitude of the earnings gains recorded by those at the very top of the income ladder.

Figure 6 portrays some of the results of these two additional effects. Note that the bottom 20 percent of earners (net of both tax and transfer payments) gained

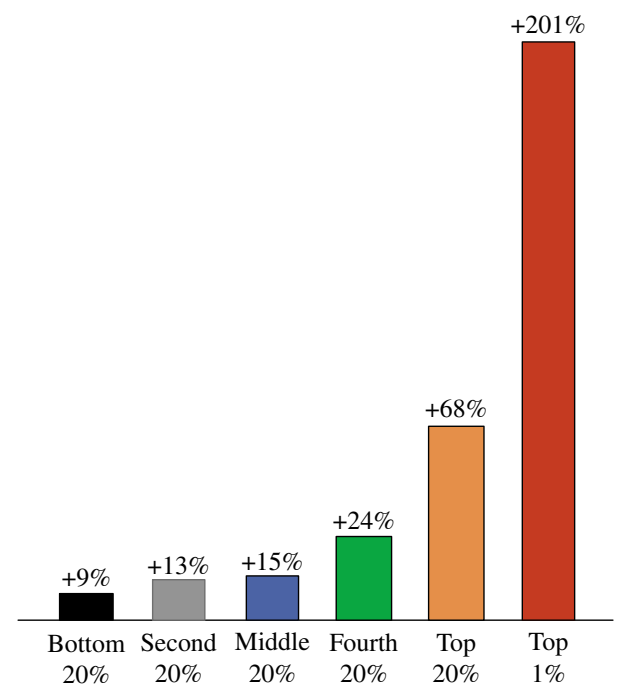

Figure 6. Change in after-tax household income, 1979-2000.

Source: Center on Budget and Policy Priorities, "The New, Definitive CBO Data on Income and Tax Trends," Sept. 23, 2003. 
slightly more ground than in Figure 5, which showed pre-tax incomes (net of transfer payments). Note also that the gains accruing to the top one percent in Figure 6 are almost three times as large the corresponding pre-tax gains experienced by the top five percent. For people in the middle quintile, however, growth in after-tax incomes occurred at essentially the same modest pace as growth in pre-tax incomes.

For the present purposes, an important feature of recent experience is that the aggregate pattern of income changes repeats itself in virtually every income subgroup. Thus, if we look at the top quintile of the earnings distribution, earnings growth has been relatively small near the bottom of that group and only slightly larger in the middle, but much larger among the top one percent. We see the same pattern again among the top one percent. In this group, the lion's share of income gains have accrued to the top tenth of one percent.

Only fragmentary data exist for people that high up in the income distribution. But a few snapshots are available. For more than 25 years, for example, Business Week has conducted an annual survey of the earnings of CEOs of the largest U.S. corporations. In 1980, these executives earned 42 times as much as the average American worker, a ratio that is larger than the corresponding ratios in countries like Japan and Germany even today. But by 2001, American CEOs were earning 531 times the average worker's salary. There is evidence that the gains have been even more pronounced for those who stand even higher than CEO's on the income ladder. $^{2}$

A similar pattern of inequality growth is observed when we look across occupations and educational groups. It shows up, for example, among college graduates, dentists, real estate agents, and high school graduates (Frank and Cook, 1995, Chapter 5). The upshot is that almost irrespective of the identities of the members of a person's personal reference group, income inequality within that group is likely to have grown sharply in recent decades. Even for the wealthiest reference groups, for which average incomes have risen most sharply, most members are thus likely to have seen their incomes decline relative to those of their most prosperous associates.

\section{Three Specific Hypotheses}

In its simplest form, the expenditure cascade hypothesis is that increasing income inequality within any reference groups leads to a reduction in the average savings

2 See, for example, Krugman (2002). As Wolff (2002), has shown, the distribution of household net worth has also be come more right-skewed in recent decades. 
rate for that group. Our attempts to test this hypothesis are grounded on the observation that income growth patterns for most population subgroups in the United States in recent decades are roughly like the one shown for the population as a whole in Figure 6. Within most groups, people at the top have enjoyed robust earnings growth, while others have seen their incomes grow much more slowly. Our claim is that the new context created by higher spending at the top of each group has caused others within the group to save a smaller proportion of their incomes.

An ideal test of this claim would examine how someone's spending responds when other members of his/her personal reference group alter their spending. But because we cannot identify the specific persons who constitute any individual's personal reference group, we are forced to rely on crude proxies.

We begin by assuming that the amount of income inequality within a person's personal reference group varies directly with the amount of inequality in the geographic area in which that group is embedded. This assumption is more palatable for narrowly defined geographic categories than for broad ones. Thus, the withinreference-group level of inequality for an individual will correspond more closely to the degree of inequality in the city in which he/she lives than to the degree of inequality in his/her home country. In one version of our study, we employ samples of persons segregated by state of residence. In another, we employ samples from the 100 most densely populated counties. Our inequality measures for both sets of jurisdictions coming from the 1990 and 2000 installments of the United States Census.

Do people who live in high-inequality jurisdictions in fact save at lower rates than those who live in low-inequality jurisdictions? Unfortunately, the Census does not record information that would enable us to construct reliable estimates of household savings rates by state or county. We are thus forced to examine alternative restatements of the hypothesis that are amenable to testing with available data.

A more general statement of the hypothesis is that families living in highinequality areas will find it harder to live within their means than their counterparts in low-inequality areas. This observation suggests that the expenditure cascades hypothesis can be tested by examining the relationships between various measures of financial distress and measures of income inequality.

Families respond to financial distress in multiple ways, some of which leave clear footprints in data available from the Census or other sources. Beyond saving at lower rates, for example, they tend to carry higher levels of consumer debt, which increases their likelihood of filing for bankruptcy. In addition, families who cannot afford to carry the mortgage payments for houses in conveniently located neighborhoods with good schools often respond by moving to cheaper, more remote neighborhoods, 
thus increasing their average commute times. And like other forms of distress, financial distress may increase the likelihood of marriages ending in divorce (and also suppress the likelihood that those people get re-married), which would mean that at any one time there will be more people divorced. We have found that for both state and county data, growth in inequality between 1990 and 2000 is positively linked with growth in each of these three measures of financial distress. But because the narrower county level data are preferable from the perspective of our theory, we report only the results of our analyses of those data. Indeed, our decision to focus on the most populous counties was also driven in part by Thorstein Veblen's (2001, p. 66) observation that "Conspicuous consumption claims a relatively larger portion of the income of the urban than of the rural population ... [because] the serviceability of consumption as a means of repute is at its best ... where the human contact of the individual is widest and the mobility of the population is greatest."

\section{Empirical Results}

In this section, we present the results of empirical studies of the links between inequality and bankruptcy, between inequality and commute times, and between inequality and divorce.

We calculated two measures of income inequality in household incomes. The first was the ratio of the 90th percentile household income to 50th percentile household income (henceforth, the P9050 ratio). ${ }^{3}$ The second is the Gini coefficient, a number between 0 and 1 that indicates the level of inequality across the entire income distribution of an area (henceforth, GINI). ${ }^{4}$ For present purposes, the Gini coefficient is the preferred inequality measure, because it is Lorenz consistent ${ }^{5}$ and accounts for the real income loss experienced by those in the lower reaches of the income distribution between 1989 and 1999, the specific time frame covered by our data. In

3 P9050 ratios for states were calculated using 1-percent microdata samples provided by the Decennial U.S. Census. The ratios for counties were estimated using income brackets. For 1990, these brackets came from 1990 Census Summary File 3, tables P80 and P80A. For 2000, see 2000 Census Summary File 3, Tables P52 and P53.

4 We used a program provided by the U.S. Bureau of the Census to calculate Gini coefficients.

5 An inequality measure is Lorenz consistent if and only if it is simultaneously consistent with the anonymity principle (permutations among people do not matter for inequality judgments), population principle (cloning the entire population and their incomes does not alter inequality), relative income principle (only relative, and not absolute, income matters), and Dalton principle (regressive transfers from poor to rich increase inequality). 
the results we report below, we thus confine our attention to regressions in which our inequality measure was based on the Gini coefficient.

To control for unobserved heterogeneity across states and counties, we constructed our regressions in first-difference form. In our bankruptcy regressions, for example, the value of the dependent variable for each area was calculated as the difference between that area's bankruptcy filings in 2000 and the corresponding number for 1990. Similarly, the area inequality variable we used was the difference between its inequality measure in 2000 and the corresponding measure in $1990{ }^{6}$ Because both years were at approximately the same point in the business cycle, we do not expect this external influence to bias our results.

Our first-difference regression models thus take the following general form:

$$
\Delta \operatorname{dep}_{i}=a+b \Delta \text { ineq }_{i}+c \Delta x_{i}+\Delta u_{i}
$$

where $\Delta \operatorname{dep}_{i}=\operatorname{dep}_{2000 i}-\operatorname{dep}_{1990 i}$, the change in the dependent variable for area $i$, $\Delta$ ineq $_{i}=$ ineq $_{2000 i}-$ ineq $_{1990 i}$, the change in the measure of income inequality for area $i$ (either the P9050 ratio or the Gini coefficient), $\Delta x_{i}$ is a vector of the corresponding changes in other possible exogenous influences on the dependent variable (with $c$ its vector of response coefficients), and $\Delta u_{i}$ is an error term, assumed i.i.d. ${ }^{7}$ The list of exogenous variables is recorded separately for each regression.

\section{$5.1 \quad$ Bankruptcy}

Individuals and married couples may file for non-business bankruptcy under Chapters 7,11 , or 13 . To assess whether increases in inequality increase the likelihood of such filings, we use the total number of adults (18 years old and above) filing for non-business bankruptcy under any of these three chapters as the basis for constructing our dependent variable. ${ }^{8}$

In addition to changes in the Gini, exogenous variables for our bankruptcy regressions include economic and socio-demographic characteristics measures employed

6 Some Decennial Census data, such as income, are for the year prior to the year of the census. In order to match income data with financial distress, we use non-business bankruptcies for 1989 and 1999. Welfare data used in the divorce regressions are from 1990 and 2000.

7 To test for heteroskedasticity, we used a special form of White's test that regresses the squared residuals of the original regression on the predicted values and the squares of the predicted values. We reject the null hypothesis of homoskedasticity if the $F$-test on the two independent variables is significant. Instead of reporting the results of this test in every regression, homoskedasticity is assumed unless otherwise stated.

8 All bankruptcy data come from the American Bankruptcy Institute's website. 
by authors in the bankruptcy literature, all translated into first-difference form (Hermann, 1966; Summers and Carroll, 1987; Fay et al., 2002; White, 2007). Economic factors include the change in the twentieth percentile earner's nominal income $(\Delta$ NomP20 $),{ }^{9}$ the change in the proportion of total households in which both husband and wife work ( $\Delta$ TwoWorker), and the change in the proportion unemployed ( $\Delta$ Unemploy). Socio-demographic characteristics include the change in average household size $(\Delta$ HHSize), the change in the proportion of total population black $(\Delta$ Black), the change in the proportion of total population Asian and Pacific Islander $(\Delta$ Asian $)$, the change in the proportion of total population ages 18-29 $(\Delta$ Age1829) and 30-54 ( $\Delta$ Age3054), and the change in the proportion of total population ages 15 and older divorced ( $\Delta$ Divorce). In addition, since the number of people filing for bankruptcy in a county is population-sensitive, we include the change in the total county population aged 18 and above as an independent variable ( $\Delta$ AdultPopulation). Finally, we include the change in population density per square mile ( $\Delta$ Density). Only the last of these variables, $\Delta$ Density, does not appear in standard bankruptcy studies. We added it to control for the possibility that it might be correlated with social forces that influence the likelihood of filing for bankruptcy. ${ }^{10}$

At the outset, we had no prior views about what functional form would best capture the relationship between income inequality and financial distress. Simple linear regressions of the change in non-business bankruptcies on changes in income inequality revealed a positive, significant relationship in both our state and most populous county samples. But the goodness of fit was generally better in regressions involving changes in the logarithm of the inequality measures. Moreover, this specification is robust across our state and county samples and facilitates easily interpretable results in terms of elasticities. In Table 1, we report the results for the $\Delta$ lnGini measures for the 100 most populous counties.

9 Lacking price index data at the county level, we were forced to use nominal income. But since the 1990s was a period of relatively low inflation, the change in nominal income for a county ought to be a good approximation for the corresponding change in real income.

10 We do not expect legislation to skew the results because most bankruptcy law occurs at the federal level, and there was no major change to federal bankruptcy law over the time period of our data (the most recent large-scale changes occurred in 1978 and 2005). One notable exception concerns what property may be considered exempt. Under the Bankruptcy Reform Act of 1978, Congress adopted a uniform federal bankruptcy exemption but allowed the states the option of setting their own exemption levels. By the time our dataset began, all states had taken this option, though some have allowed filers the option to choose either the federal or state exemption level. As noted by Fay et al. (2002), states only rarely change their exemption levels, and most changes are designed to simply preserve the real values of these levels. 
The coefficient for $\Delta$ lnGini suggests that, as hypothesized, changes in income inequality are positively and significantly associated with changes in the number of non-business bankruptcy filings in our sample of the 100 most populous counties. A one percent increase in the Gini coefficient is associated with a 7.39 percent rise in the number of non-business bankruptcies. This is a remarkably strong effect. For our sample of the 100 most populous counties, the Gini coefficients increased by an average of 4.41 percent between 1990 and 2000. Our estimate thus implies that increased inequality in these counties was associated with a 33 percent increase in bankruptcy filings between 1990 and 2000. This estimate seems reasonable given that, on average, non-business bankruptcies increased 148 percent in our sample.

Note also in Table 1 that changes in the absolute income of the 20th percentile earner are negatively and significantly associated with changes in bankruptcy filings. This finding is consistent with the traditional view that families with more money should be better able to meet their financial obligations. But the effect is small,

Table 1. The relationship between inequality and non-business bankruptcy.

Dependent variable: Change in the natural logarithm of the number of non-business bankruptcies.

Sample: 100 most populous counties.

\begin{tabular}{lcccc}
\hline Independent variable & Coefficient & Standard error & $T$-statistic & $P$ \\
\hline Constant & 0.307 & 0.206 & 1.49 & 0.140 \\
$\Delta$ lnGini & 7.391 & 2.256 & 3.28 & 0.002 \\
$\Delta$ NomP20 & $-8.02 \mathrm{e}-5$ & $2.46 \mathrm{e}-5$ & -3.26 & 0.002 \\
$\Delta$ Density & $4.26 \mathrm{e}-5$ & $2.57 \mathrm{e}-5$ & 1.66 & 0.101 \\
$\Delta$ lnAdultPopulation & 1.185 & 0.447 & 2.65 & 0.010 \\
$\Delta$ Black & -2.102 & 1.506 & -1.40 & 0.166 \\
$\Delta$ Asian & -1.545 & 2.682 & -0.58 & 0.566 \\
$\Delta$ TwoWorker & 0.083 & 3.107 & 0.03 & 0.979 \\
$\Delta$ Unemploy & 1.714 & 3.549 & 0.48 & 0.630 \\
$\Delta$ Age1829 & -7.318 & 3.454 & -2.12 & 0.037 \\
$\Delta$ Age3054 & 10.633 & 6.150 & 1.73 & 0.087 \\
$\Delta$ Divorce & 3.839 & 8.294 & 0.46 & 0.645 \\
$\Delta$ HHSize & -1.492 & 0.747 & -2.00 & 0.049 \\
\hline
\end{tabular}

$R^{2}=0.5206$, Adj $R^{2}=0.4545$ 
and does not rule out the notion that a family's desired consumption may increase hand in hand with income. Although the $\Delta$ Density variable is not statistically significant at conventional levels, this may reflect the existence of threshold effects, since density is extremely high in most of the 100 most populous counties.

\subsection{Divorce}

The dependent variable in our divorce regressions is the change in the proportion of the total area population aged 15 and above that is currently divorced. In these regressions, too, we include the standard economic and socio-demographic factors discussed by other authors in the relevant literature (e.g., Friedberg, 1998; Stevenson and Wolfers, 2006, 2007). ${ }^{11}$ The main economic factor is the change in the $\log$ of the maximum state welfare benefit for a family of three, which captures the impact of the 1996 welfare reform that gave states greater latitude in distributing welfare benefits ( $\Delta$ LNWelfare). The socio-demographic factors include the change in the proportion of total population aged 25 and above with at least a bachelor's degree $(\Delta \mathrm{Edu})$, the change in the proportion of women aged 16 and above in the labor force $(\Delta$ WomenLF), the change in the proportion of total households receiving retirement income ( $\Delta$ Retinc), the change in the average household size $(\Delta$ HHSize $)$, the change in the proportion of total population black $(\Delta$ Black $)$, the change in the proportion of total population Asian and Pacific Islander $(\Delta$ Asian), and the change in the age distribution (captured by $\Delta$ Age1829 and $\Delta$ Age 3054 ). ${ }^{12}$

Again our findings for the state and county regressions were broadly similar, with generally better goodness of fit for the county regressions. Table 2 reports our results for the $\Delta \ln$ Gini specification for the 100 most populous counties.

11 To be sure, much of this literature seeks to explain changes in the divorce rate, which is not the same as the proportion of people that are currently divorced at one time. With that in mind, we have sought in our models to account for some of the major economic and sociodemographic characteristics associated with people's likelihood of getting married in the first place and/or getting re-married after having been divorced (see Stevenson and Wolfers, 2007 for a summary). The data set we are using only includes current marital status, and not marital history.

12 The two age variables capture two separate factors: people are marrying later (and clearly marriage is a prerequisite for divorce) and people who are older are more likely to be divorced at any one time (because they have actually been married in the first place). People who are 55 years old and older is our omitted category. Separately, we do not expect differences in state divorce legislation to skew these results, as the largest change in divorce laws in recent times the adoption of unilateral divorce and no-fault divorce - occurred prior to the start of our data set. The bulk of these changes occurred in the 1970s, which means that they had been in place for over one decade by the time our data set began. 
Table 2. The relationship between inequality and proportion currently divorced. Dependent variable: Change in the natural logarithm of the proportion of total population aged 15 and above currently divorced.

Sample: 100 most populous U.S. counties.

\begin{tabular}{lcccc}
\hline Independent variable & Coefficient & Standard error & $T$-statistic & $P$ \\
\hline Constant & 0.003 & 0.022 & 0.12 & 0.906 \\
$\Delta$ lnGini & 0.493 & 0.287 & 1.72 & 0.089 \\
$\Delta$ lnWelfare & 0.064 & 0.057 & 1.13 & 0.263 \\
$\Delta$ Edu & -0.914 & 0.284 & -3.22 & 0.002 \\
$\Delta$ WomenLF & 0.806 & 0.366 & 2.20 & 0.030 \\
$\Delta$ Retinc & 1.616 & 0.756 & 2.14 & 0.035 \\
$\Delta$ HHSize & -0.409 & 0.091 & -4.47 & 0.000 \\
$\Delta$ Age1829 & -1.042 & 0.499 & -2.09 & 0.040 \\
$\Delta$ Age3054 & 3.156 & 0.901 & 3.50 & 0.001 \\
$\Delta$ Black & 0.175 & 0.195 & 0.90 & 0.372 \\
$\Delta$ Asian & 0.109 & 0.353 & 0.31 & 0.758 \\
\hline
\end{tabular}

$R^{2}=0.6966$, Adj $R^{2}=0.6625$

Note in Table 2 that a one percent rise in the Gini coefficient is associated with a 0.49 percent increase in the proportion of divorced persons in highly populated counties. Given that the average change in the Gini coefficient between 1990 and 2000 was 4.41 percent for counties in our sample, the estimate implies that increased inequality was associated with a 2.16 percent increase in the number of divorces during this period.

\subsection{Travel Time to Work}

In these regressions, our dependent variable is the change in the proportion of all workers aged 16 and over whose daily commute is one hour or more. Here again we include a variety of economic and demographic characteristics that are known to affect travel time to work (e.g., Khattak et al., 2000; Levinson and Kumar, 2006). We include changes in nominal median income to capture changes in the general state of the area economy $(\Delta$ NomP 50$)$. Because of studies finding a positive 
relationship between race and commute time, particularly for African-Americans, ${ }^{13}$ we control for racial characteristics by including the change in the proportion of total population white ( $\Delta$ White) and the change in the proportion of total population black $(\Delta$ Black). We also include the change in the density of the population $(\Delta$ Density), this time to control for changes in congestion on the roads and in the public transit systems. Finally, we include the change in the proportion of total population receiving retirement income ( $\Delta$ Retinc), to control for the portion of the population that is probably not commuting.

Again the results for the state and county regressions were broadly similar. Unlike the earlier regressions, however, we found that $\Delta$ Gini provided a somewhat tighter fit than $\Delta \ln$ Gini in these regressions and was more robust across our state and county samples. Table 3 reports our results for that specification for the 100 most populous counties.

The estimated coefficient for $\Delta$ Gini suggests that, as hypothesized, increases in income inequality are positively associated with changes in financial distress, as manifested in this instance by decisions to buy cheaper, but less conveniently located, housing. For counties in our sample, the Gini coefficient went up by an

Table 3. The relationship between inequality and proportion having a long commute.

Dependent variable: Change in the proportion of total workers aged 16 and above with one hour or longer daily commute.

Sample: 100 most populous counties.

\begin{tabular}{lccrr}
\hline Independent variable & Coefficient & Standard error & $T$-statistic & $P$ \\
\hline Constant & $-2.84 \mathrm{e}-3$ & $5.62 \mathrm{e}-3$ & -0.51 & 0.615 \\
$\Delta$ Gini & 0.392 & 0.153 & 2.56 & 0.012 \\
$\Delta$ NomP50 & $9.93 \mathrm{e}-7$ & $3.61 \mathrm{e}-7$ & 2.75 & 0.007 \\
$\Delta$ White & -0.056 & 0.047 & -1.19 & 0.237 \\
$\Delta$ Black & 0.158 & 0.063 & 2.49 & 0.014 \\
$\Delta$ Density & $-1.19 \mathrm{e}-7$ & $9.68 \mathrm{e}-7$ & -0.12 & 0.902 \\
$\Delta$ Retinc & -0.351 & 0.164 & -2.14 & 0.035 \\
\hline
\end{tabular}

$R^{2}=0.2688$, Adj $R^{2}=0.2217$

13 Ibid. 
average of 0.018 between 1990 and 2000. Our estimate thus implies that increased inequality is on average associated with an increase of 0.0071 in the proportion of adults with commutes longer than one hour, which (for example) would translate to over 7000 people in a county with one million workers aged 16 and above.

\section{Discussion}

The simple expenditure cascade mechanism just illustrated is also consistent with international savings rate comparisons patterns that are not predicted by the permanent income hypothesis. The aggregate savings rate, for example, was lower in the United States than in Europe in 1980, and the gap has grown larger during the ensuing years. That pattern mirrors the corresponding cross-national pattern in the inequality data. Income inequality was higher in the United States than in Europe in 1980, and the gap is wider today than it was then.

The expenditure cascade model is also consistent with detailed patterns in cross section data that are not predicted by the permanent income hypothesis. For example, as James Duesenberry observed in his 1949 book, a black family with a given absolute income would have higher relative income in the segregated neighborhoods of his era than a white family with the same absolute income. And as Duesenberry predicted, the savings rates of black families with a given income level were higher than those of white families with the same income. The permanent income hypothesis and the life cycle hypothesis, both of which disavow any role for context in consumption decisions, predict that families will save at the same rate irrespective of race.

Do expenditure cascades imply irrational consumers? Some economists object that concerns about relative consumption can affect savings rates in the manner described only if consumers are myopic. After all, if a consumer is induced to spend more today because of higher current spending by others, he/she will have even lower relative consumption in the future. Perhaps so. But it may still be rational to be responsive to community consumption standards.

Consider, for example, the fact that in most communities, the median family on the earnings scale now pays much more for housing, in real terms, than its counterpart in 1980. This family would find it easier to live within its means if it simply spent less on housing than others in the same income bracket. But because the quality of public schools in the United States is closely linked to local property taxes, which in turn depend on local real estate prices, this family would then end 
up having to send its children to below-average schools. ${ }^{14}$ In the same vein, a job seeker could live more comfortably for the time being by refusing to match the increased expenditures of others on interview suits. Yet doing so would entail a reduced likelihood of landing the best job for which he was qualified. It is thus by no means clear that being influenced by community consumption standards implies myopia.

On the other hand, there is considerable evidence that myopia is a salient feature of human psychology (Pigou, 1929; Ainslie, 1992; Laibson, 1998; O'Donoghue and Rabin, 1999). The pain of enduring lower relative living standards today can be experienced directly. In contrast, the pain of enduring lower relative standards in the future can only be imagined. In the end, first principles cannot answer the question of whether higher spending by some people induces others to spend more. We must answer this question empirically.

\section{References}

Ainslie, G. 1992. Picoeconomics. New York: Cambridge University Press.

Bernheim, B. D., J. Skinner, and S. Weinberg. 2001. "What Accounts for the Variation in Retirement Wealth Among U.S. Households?" American Economic Review 91: 832-857.

Bowles, S. and Y. Park. 2005. "Emulation, Inequality, and Work Hours: Was Thorstein Veblen Right?" Economic Journal 115: F397-F412.

Bodkin, R. G. 1959. "Windfall Income and Consumption." American Economic Review 49: $602-614$.

Carroll, C. D. 1998. "Why Do the Rich Save So Much?" In Does Atlas Shrug: The Economic Consequences of Taxing the Rich, Joel Slemrod, (ed.), New York: Oxford University Press.

Diamond, P. A. and J. A. Hausman. 1984. "Individual Retirement and Savings Behavior." Journal of Public Economics 23: 81-114.

Duesenberry, J. 1949. Income, Saving, and the Theory of Consumer Behavior. Cambridge, MA: Harvard University Press.

Fay, S., E. Hurst, and M. J. White. 2002. "The Household Bankruptcy Decision." American Economic Review 92: 706-718.

Frank, R. H. 1985. Choosing the Right Pond. New York: Oxford University Press.

Friedberg, L. 1998. "Did Unilateral Divorce Raise Divorce Rates? Evidence from Panel Data." American Economic Review 83: 608-627.

Friedman, M. 1957. A Theory of the Consumption Function. Princeton, NJ: Princeton University Press.

14 In light of evidence that any given student's achievement level rises with the average socioeconomic status of his/her classmates, property values and school quality will be positively linked even in jurisdictions in which school budgets are largely independent of local property values. 
Herrmann, R. O. 1966. "Families in Bankruptcy, A Survey of Recent Studies." Journal of Marriage and the Family 28: 324-330.

Khattak, A. J., V. Amerlynck, and R. G. Quercia. 2000. "Are Travel Times and Distances to Work Greater for Residents of Poor Urban Neighborhoods?" Transportation Research Record 1718: 73-82.

Krugman, P. 2002. "For Richer: How the Permissive Capitalism of the Boom Destroyed American Equality." New York Times Magazine October 20, 62-142.

Laibson, D. 1998. "Life Cycle Consumption and Hyperbolic Discounting Functions." European Economic Review Papers and Proceedings 42: 861-871.

Levinson, D. M. and A. Kumar. 2006. "Density and the Journey to Work." Growth and Change 28: 147-172.

Liviatan, N. 1963. "Tests of the Permanent-Income Hypothesis Based on a Reinterview Savings Survey." In Measurement in Economics: Studies in Mathematical Economics and Econometrics in Memory of Yehuda Grunfeld, Carl F. Christ et al., (eds.), Stanford, CA: Stanford University Press, pp. 29-59.

Mayer, T. 1966. "The Propensity to Consume Permanent Income." American Economic Review 56: 1158-1177.

Mayer, T. 1972. Permanent Income, Wealth, and Consumption. Berkeley: University of California Press.

Modigliani, F. and R. Brumberg. 1955. "Utility Analysis and the Consumption Function: An Interpretation of Cross-Section Data." In Post-Keynesian Economics, K. Kurihara, (ed.), London: Allen and Unwin.

O'Donoghue, T. and M. Rabin. 1999. "Doing It Now or Later." American Economic Review 89: 103-124.

Ostvik-White, B. 2003. "Income Inequality and Median House Prices in 200 School Districts." Cornell University Institute of Public Policy Masters Thesis, Ithaca, NY.

Pigou, A. C. 1929. The Economics of Welfare. London: Macmillan.

Smeeding, T. M. 2001. "The Gap Between Rich and Poor: A Cross-national Perspective on Why Inequality Matters and What Policy Can Do To Alleviate It." prepared for the National Institute of Social Security Research, Tokyo, Japan, March 21.

Stevenson, B. and J. Wolfers. 2006. "Bargaining in the Shadow of the Law: Divorce Laws and Family Distress." Quarterly Journal of Economics 121: 267-288.

Stevenson, B. and J. Wolfers. 2007. "Marriage and Divorce: Changes and Their Driving Forces." The Journal of Economic Perspectives 21: 27-52.

Summers, L. H. and C. Carroll. 1987. "Why is U.S. National Saving So Low?" Brookings Papers on Economic Activity 2: 607-635.

Thaler, R. and H. M. Shefrin. 1981. "An Economic Theory of Self-Control." Journal of Political Economy 89: 392-405.

Veblen, T. 2001. The Theory of the Leisure Class, 1899. Alan Wolfe, (ed.), New York: The Modern Library.

White, M. 2007. "Bankruptcy Reform and Credit Cards." The Journal of Economic Perspectives 21: 175-200.

Wolff, E. N. 2002. Top Heavy: A Study of Increasing Inequality of Wealth in America. NY: The New Press. 